\title{
FRAGMENTO DE CUENCO CAMPANIFORME APARECIDO EN BUENDIA (CUENCA)
}

\author{
Santiago Valiente Cánovas
}

Merced a don Fernando Molina Pérez, que desarrollaba su afición cinegética en las cercanías del pueblo de Buendía, en la provincia de Cuenca, fueron recogidos por el citado señor varios fragmentos de cerámica, en las proximidades a la orilla del pantano, entre los que destaca un fragmento de cuenco de la Cultura del Vaso Campaniforme.

Los objetos fueron enviados al departamento de Arqueología por don Fernando Valdés.

Nos personamos en el citado pueblo y recorrimos las orillas del pantano en las cercanías donde se efectuó el hallazgo, observando, cómo en las márgenes se hallaban depositados un buen número de fragmentos cerámicos de cronología reciente y otros de factura tosca, de cronología más o menos antigua. Todos ellos procedían del arrastre de las aguas del pantano y en su mayoría eran vidriados.

$\mathrm{La}$ distancia a la que aparecieron fue a unos ocho metros en línea recta del nivel actual del agua y no se aprecia que en los alrededores existan restos de construcciones, poblados o necrópolis que puedan aportar algún dato sobre su procedencia.

\section{CONTEXTO ARQUEOLÓGICO DE LOS ALREDEDORES}

Conserva el pueblo de Buendía parte de su recinto amurallado y algunas de sus puertas de entrada flanqueadas por torreones (lámina I).

En las cercanías del pantano existen un grupo de cuevas artificiales, 
de posible interés arqueológico, que han servido hasta hace poco para la recogida del ganado.

Las excavaciones y hallazgos prehistóricos próximos a Buendía han sido escasos y tal vez por eso no se les ha concedido la debida importancia.

Destaca en las proximidades del pueblo de Cañaveruela la ciudad romana de Ercávica, cuya primera campaña de excavación (1) dio importantes hallazgos escultóricos de época imperial romana, tanto en piedra como en bronce. También se excavaron varias tumbas medievales de carácter judaizante en la misma zona.

Otras necrópolis se excavaron en las cercanías de Riba de Saelices (2), ya en el término de la provincia de Guadalajara, y Zorita de los Canes (3), donde se hallaron importantes ajuares visigodos, ambas en zonas próximas a Buendia.

Por último, noticias sueltas de hallazgos arqueológicos de la provincia de Cuenca pueden verse en los inventarios de los Noticiarios Arqueológicos Hispánicos, tomos I, II, VI y VII, correspondientes respectivamente, a los años 1952, 1953, 1962 y 1963.

\section{DESCRIPCIÓN}

El hallazgo fortuito al que nos referimos es un fragmento del borde de un cuenco (Fig. 1). Su pasta es negra con restos de paja y gruesos desgrasantes de cuarzos micas y areniscas, que se aprecian claramente en ambas superficies; la exterior presenta decoración y su cochura es irregular, mientras que la interior está más cuidada y es de color gris, algo más claro que la pasta.

La decoración incisa es de bandas paralelas que comienzan a cuatro milímetros del borde, con pequeñas líneas transversales y paralelas entre ellas; a continuación un ajedrezado a base de cuadrados que dan la sensación de claro oscuro; inmediatamente debajo, vuelven a repetirse

(1) Osuna Ruiz, M.: Excavaciones en el Castro de Santaver (Ercáviga). XIII C. A. N. Huelva, 1973.

(2) Cuadrado, Emeterio: Las excavaciones de la necrópolis de Riba de Saelices (Guadalajara). "Noticiario Arqueológico Hispánico", VIII y IX, cuadernos 1-3, 1964-65. Madrid, 1966; págs. 158-161.

(3) Cabré Águiló, J.: El tesorillo visigodo de Trientes de las excavaciones del Plan Nacional de 1944-45, en Zorita de los Canes (Guadalajara). Informes y Memorias de la Comisaría General de Excavaciones Arqueológicas, X, 1946. 
las líneas transversales, seguidas de una línea de incisiones Sormando rombos y, por último, vuelven a aparecer las líneas trausversales.

$\mathrm{El} \mathrm{fragmento} \mathrm{presenta} \mathrm{posibles} \mathrm{incrustaciones} \mathrm{de} \mathrm{pasta} \mathrm{blanca} \mathrm{irregu-}$ larmente conservada entre la decoración incisa.

Medidas: diámerro de la boca, $95 \mathrm{~mm}$; altura aproximada, $4 \mathrm{~mm}$., y espesor de la pasta, $5 \mathrm{~mm}$.

Junto al cuenco incompleto, se recogieron varios fragmentos cerámicos muy rodados, hechos a torno, de pastas rojizas, grises y negras. Destaca entre todos ellos uno de paredes muy gruesas, con la pasta del exterior al interior, parda, negra y rojiza; esta última, con desgrasantes muy gruesos de cuarzo. La superficie exterior es parda, con irisaciones rojizas, muchas concreciones y tiene un orificio circular. La superficie interior es parda con tonos rojizos y con zonas desconchadas. (Medidas: longitud de lo conservado, $70 \mathrm{~mm}$.; grosor de la pasta, $18 \mathrm{~mm}$., y diámetro del orificio, $0,8 \mathrm{~mm}$.)

\section{PaRALELOS Y CRONOLOGía}

Este tipo de cuenco se da a lo largo de todas las etapas de la Cultura del Vaso Campaniforme.

Los paralelos más inmediatos en la Península hay que buscarlos en las excavaciones realizadas en los alrededores de Madrid, que dan una enorme cantidad de cuencos (4) y en especial en Ciempozuelos.

Existen también paralelismo con los cuencos de Algodor (Toledo), Palmella, Acebuchal y Estoril, en Portugal (5), y el valle del Guadalquivir.

Establecer una cronología es difícil, ya que se trata de un hallazgo aislado, sin lugar exacto de procedencia, recogido con otras cerámicas de distintas facturas y épocas $y$, por otra parte, hay que tener en cuenta toda la problemática planteada hoy día en cuanto al origen, difusión, paralelismos culturales y cronología del Vaso Campaniforme.

No obstante, por forma y decoración, parece pertenecer al tipo «es-

(4) En el Museo de la Fuente del Berro de Madrid hay una gran colección de vasos y cuencos de la Cultura del Vaso Campaniforme, procedentes de varios lugares de la provincia de Madrid; varios de ellos muestran semejanzas en forma y decoración con el cuenco de Buendía.

(5) Leisner, G. V.: Die Megalithgräber der Iberischen Halbinsel I. Der Süden («Römisch-Germanische Forschungen»), 17. Berlín, 1943. Ver lámina 7, figs. 2, 12. Der esten, I (íd. Berlín, 1959), II, I 3 (Deutsches Archacologisches Institut Abteilung). Madrid, Berlín, 1956. 
tilo Ciempozuelos», que Sangmeister (6) incluye en el grupo "pan-europeo» y que se originó en el Bajo Rhin e Inglaterra y mediante un «reflujo» pasó al Oeste de Europa. Se fecha ya en plena Edad de Bronce en la Península.

En la clasificación de Bosch Gimpera (7), se incluiría en el tipo II, característico por las decoraciones aún correctas, con incisiones profundas, y que se extendería por la Meseta Central, y más aún por los alrededores de Madrid, Cataluña, Andalucía y Portugal con la penetración dolménica. Su origen estaría en Andalucía y desde allí se propagaría hacia el Mediterráneo Occidental y por Francia hacia Europa Central. Su fecha oscilaría entre dos mil quinientos y dos mil trescientos a. de JC. según el $\mathrm{C}_{14}$.

Alberto del Castillo (8) hoy día, al igual que Sangmeíster, llega a considerar el tipo I, es decir, el "clásico de Ciempozuelos", en plena Edad del Bronce español o Bronce Inicial europeo, dando una fecha que oscilaría entre 1850-1600.

Es poco cuanto se puede decir de este hallazgo, a excepción del interés que presenta el contar con un nuevo ejemplar que nos evidencia una vez más, la vasta difusión de este tipo de cerámica.

(6) Sangmeister: La civilisation du Vase Campaniforme. Les Civilisations Atlantiques. Rennes, 1963 ;págs. 25-55, fig. 18. Die Datierung des Rückstroms der Glockenbecher und ihre Auswirkung auf die Chronologie der Kupferzeit in Portugal. Palaeohistoria XII, págs. 396-407. Groningen, 1966.

(7) Bosch Gimpera: Tipos y cronología del Vaso Campaniforme. Archivo Es. pañol de Arqueología, año 1971, t. núm. 44, págs. 3-37.

(8) Castillo, A. del: Las tres capas de la cueva de Somaén. Archivo de Prehistoria Levantina. Valencia, 1953; págs. 149-50. 


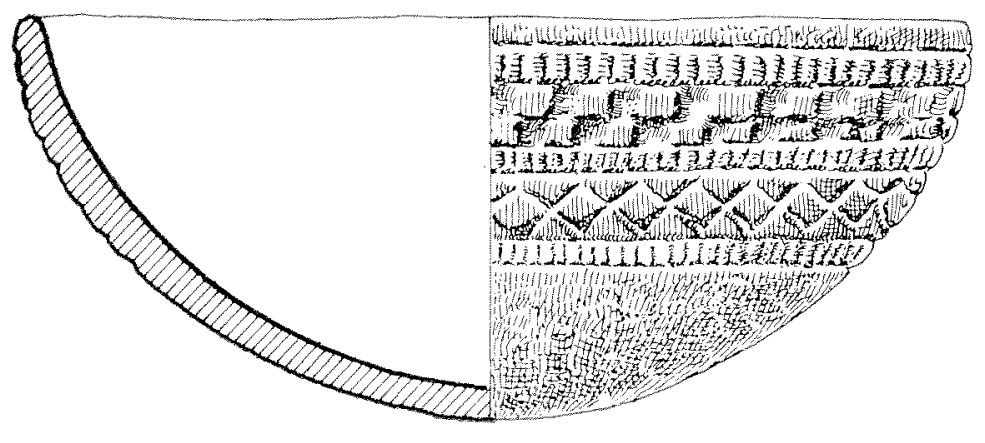

Fig. I 

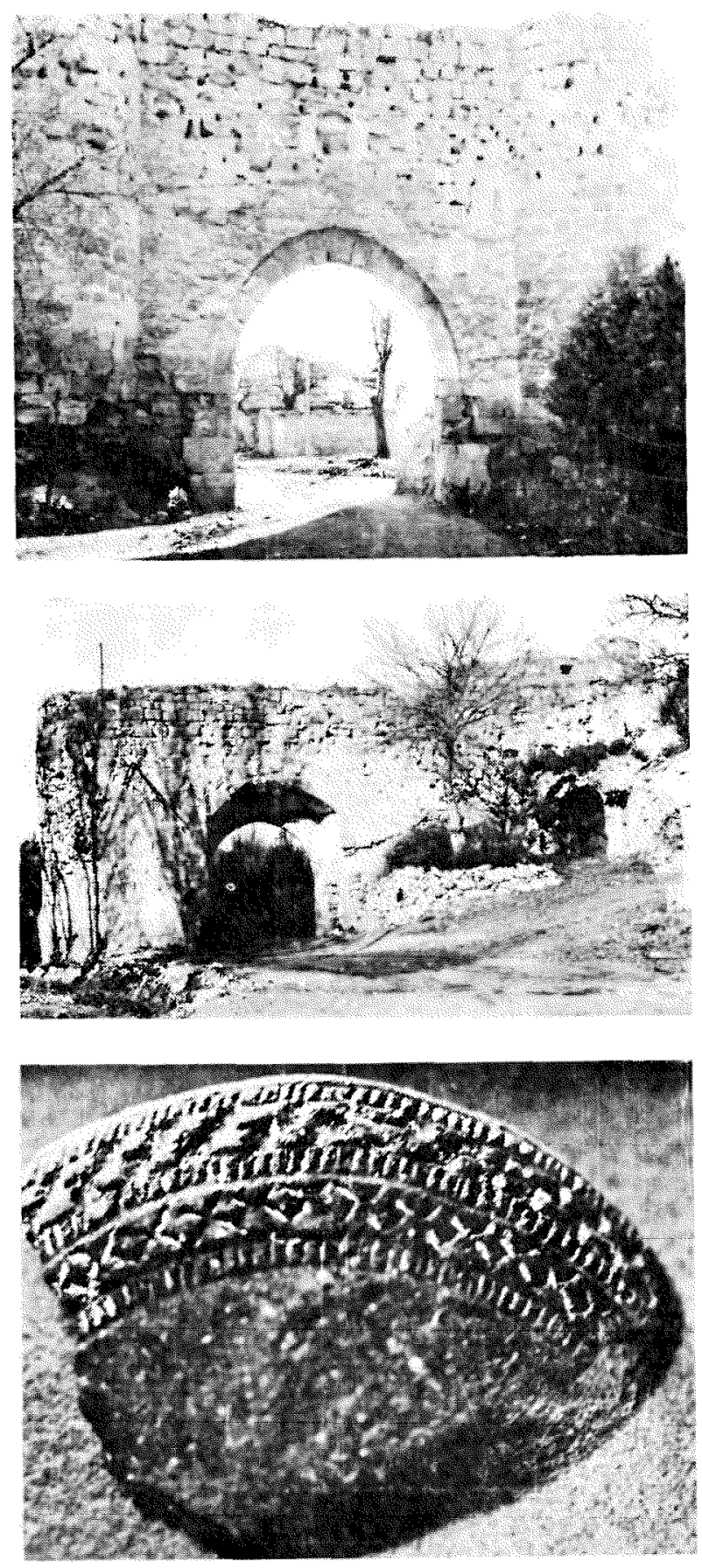

1) Vista de una de las puertas del recinto de muralla de Buendia.

2) Vista desde el interior de la misma puerta.

3) Fragmento de cuenco campaniforme. 